\title{
Validity and Reliability of Micro-controller based BIA Instrument for Assessment of Upper and Lower limb in Male Subjects at Multi-Frequency
}

\author{
Charu Pawar',*, Munna Khan², J.P. saini ${ }^{3}$ \\ *Corresponding Author: charu.pwr@gmail.com \\ ${ }^{1}$ Dr. A P J Abdul Kalam Technical University, Lucknow \\ 2Jamia Millia Islamia University, New Delhi, India \\ ${ }^{3}$ NSUT, New Delhi, India
}

\begin{abstract}
The purpose of this study was to validate the resultant data for assessment of upper and lower limb for male subjects, using developed microcontroller based bioelectrical impedance analysis (BIA) instrument with standard device (Microprocessor based 4 channel auto mode T.E.N.S unit) at multi-frequency. Twenty-two male subjects of age 21-45 years were taken under the examination. Data measured by developed BIA instrument is validated with data recorded by standard device. The recorded data represent that the measured data varies with frequencies. The frequencies used for the measurement were $5 \mathrm{KHz}, 50 \mathrm{KHz}, 100 \mathrm{KHz}, 250 \mathrm{KHz}$, and $500 \mathrm{KHz}$. The results indicates that impedance of upper and lower limb change according to the frequency variations, and reduces with the increment of the different frequencies. A result also indicates that impedance of the left limb is greater than the impedance of the right limb. The results analysis of upper limb shows that error percentage between developed BIA instrument and standard device is less than $1.93 \Omega$ for left arm and less than $1.50 \Omega$ for the right arm at the same frequencies. The result analysis of lower limb shows that mean error percentage between both instruments, for left leg is less than $3.37 \Omega$ and less than $2.78 \Omega$ for right leg.
\end{abstract}

Keywords: Bioelectrical impedance analysis, Multi-frequency, T.TE.N.S, KHz.

\begin{tabular}{|l|l|l|l|}
\hline \multicolumn{2}{|l|}{ NOMENCLATURE } & & \\
\hline$\mu \mathrm{A}$ & Micro ampere & NG & Normal group \\
\hline $\mathrm{KHz}$ & Kilo hertz & OG & Osteoarthritis group \\
\hline $\mathrm{K} \Omega$ & Kilo ohms & BIMS & Bioelectrical impedance measurement system \\
\hline $\mathrm{mA}$ & Mili ampere & ECF & Extracellular fluid \\
\hline $\mathrm{MHz}$ & Mega hertz & ICF & Intracellular fluid \\
\hline $\mathrm{Cm}$ & Centimetre & TBW & Total body water \\
\hline $\mathrm{L}_{\mathrm{R}}$ & Load resistance & ACCS & Adjustable Constant Current source \\
\hline $\mathrm{R}$ & Resistance & A/D converter & Analog to digital converter \\
\hline XC & reactance & AGC & Automatic Gain Control \\
\hline $\mathrm{Re}$ & Extra-cellular resistance & TINA-TI & Toolkit for Interactive Network Analysis \\
\hline $\mathrm{Z}$ & impedance & RS-232 & Recommended serial \\
\hline Xcx & equivalent capacitance & SPICE & Software Process Improvement and Capability \\
\hline $\mathrm{A}$ & Area & PCB & Printed circuit board \\
\hline $\mathrm{L}$ & Length & 3D & Three dimensions \\
\hline$\rho$ & Specific resistivity & AM & Ammeter \\
\hline V & Volume & VG & Ground voltage \\
\hline Abbreviation & & Vsine & \\
\hline BI & Bioelectrical impedance & VM & Voltmeter \\
\hline OA & Osteoarthritis & NG & Normal group \\
\hline BIA & Bioelectrical Impedance Analysis & OG & Osteoarthritis group \\
\hline T.E.N.S & Transcutaneous Elictircal Nerve & & \\
\hline & Stimulation & & \\
\hline
\end{tabular}




\section{INTRODUCTION}

The bio-electrical impedance of the human body shows embodied condition of body cells. The existing literature is helpful to understand the different methodologies and standards for the bio-electrical impedance measurement [1]. In rural areas, $10 \%$ of villages and $27-28 \%$ of district peoples are suffering from different type of joint problems because of their overweight and sometimes due to underweight in case of imbalance body growth. The surveys clearly said that India facing joint diseases in both cases as first due to obesity and second due to the bad alimentation. The population going through these types of situations stands at dead-line of joint diseases [2]. Most people who suffer from joint disease face different body disaster as, immobility of some of the body segments, morning stiffness in the body, joint pain, swelling, and ruggedness. They become dependent on others. The regular monitoring of the body in the form of regular measurement impedance of the human body or joint, proof-like support to prevent these diseases. In other words, regular measurement of the bio-electrical impedance of the human body makes an ordered series to know about their recovery and healing from these diseases [3]. Some of the research suggests that if $5 \mathrm{~kg}$ weight reduced from a standard range of Body mass index (BMI) in obese and overweight people, it makes big support to avoid $24 \%$ surgical cases in case of knee osteoarthritis. Early detection of arthritis also prevents from surgery [4]. The methods available for the measurement of bio-electrical impedance are based on the number of electrodes as a two-electrode method, three-electrode methods, four electrode methods, and eight electrodes method, among of them, four electrodes method is most popular because it reduced interfacing between skin and electrodes. Due to this method measurement accuracy increases [5]. The BMI related to joint problems as early as 20 years in men and 11 years in women. The researchers suggest that high BMI is risky for adults. To prevent the problems of legs, weight control is primarily necessary [6]. The osteoarthritis (OA) reaches a hazard factor due to a high body mass index for a long time. The mass index can control with the help of regular monitoring of the body [7]. The single frequency and multi-frequencies are used to measure the segmental or whole-body bioelectrical impedance of the human body. The literature shows that single frequency not suitable to provide accurate internal fluid conditions of the body so multi-frequency replace because of this deficiency of single frequency. The single low frequency cannot find out the internal position of body cells due to low frequency as it can flow only outside the cell.
Inversely, high frequency can easily flow inside the cells to know about the internal position, so multifrequency used more than the single frequency for the measurement of body composition parameters [8]. The observation of measured values of total body water (TBW) and fat-free mass (FFM) define that predicted values at $50 \mathrm{kHz}, 100 \mathrm{kHz}$ and $200 \mathrm{kHz}$ are nearly equal to measured values, than the measured values at $5 \mathrm{kHz}$ frequency. The reason behind this is that at low frequencies, current cannot cross the cell membrane and flow only in extracellular fluids although high frequencies strike the cell membrane and currently conducted through intracellular and extracellular fluids [9]. Multi-frequency used to measure body composition parameters like FFM and TBW, so $50-300 \mathrm{kHz}$ range normally used to diagnose body tissues [10].

On the other hand, segmental bio-electrical impedance said better than whole-body impedance, as analysis of a specific segment of the body is possible with segmental impedance [11]. The segmental impedance gives detailed information about a particular body part or joint of the human body, which can become supportable for correct treatment and solution. The techniques for the measurement of bio-electrical impedance in the human body are Bio-electrical impedance analysis (BIA), Dual-energy x-ray absorptiometry (DXA), Magnetic resonance imaging (MRI), or Computed Tomography (CT) [12]. The present research use BIA methods. A significant measurement of fat mass (FM), with the use of BIA, can reduced clinically injuries [13]. The bio-electrical impedance analysis (BMI) shows a compatible correlation between both sexes in the estimation of fat mass and fat-free mass [14]. It is found that percent body fat $(\% \mathrm{BF})$, underestimated for normal body mass index and $\% \mathrm{BF}$, and overestimated for obese BMIs and overweight mass index. Segmental bioelectrical is useful to know about that how any segment of body effects from any diseases and also helpful to diagnose to change in a different type of body composition parameters like mass of particular segments mass and fat [15]. The BIA foot-to-foot method accurately predicts different fat levels in Asian healthy individuals. In obese people, BIA also calculates fatfree mass. Already existing research shows that the obesity parameter scale affects the accuracy of BIA in individuals [16]. The fat mass for arm and leg consider underestimated and overestimated lean mass for arm and trunk according to the measurement of BIA [17]. Some of the studies report that resistance and reactance of different segments of the body directly correlated to \%BF and at the same note BMI also highly correlated with \%BF [18]. The assessment of bio-electrical impedance of leg and 
arm is more useful than the trunk as analysis of fatfree mass in obese and non-obese women is accurate. The literature said that BIA and under-water weight, of a woman, is almost the same if the prediction of fat-free mass of women who follow the diet or combined it with exercise [19]. The variables of bioelectrical impedance (BI) are inversely proportional to body mass index (BMI). BI not affects the relation between BMI and electrode placement [20]. The routine measurement of impedance becomes helpful to inform about healing progress of fractured or healthy bone. The impedance of fractured bone is more than a healthy bone. The regular checkup makes a marker for healing of diseases [6]. The improvement in healing and recovery of a group suffering from diseases also depends on BMI of the body, as if BMI of a body decrease then fast improvement occurs in pain but at increment in BMI, healing takes time [21].

\section{MATERIALS AND METHODS}

This section shows different modes for bioelectrical impedance measurements.

\section{(2.1) BASIC PRINCIPLE OF SEGMENTAL BIOELECTRICAL IMPEDANCE MEASURING}

The theory of Ohm's Law reveals that, concerning human body, the Source known as voltage (used to insert current into the human body), which produced between different point in body fluids, apart from this term Sink is known as current, which flows between two electrodes (used to detect the current response [22]. Fig.1(a) shows an equivalent circuit of the body cells with intra cellular and extra cellular fluid. As shown in Fig.1 (a) C stands for the capacitance of cell membrane connected in series of resistance $\mathrm{Ri}$ of intra-cellular fluid (ICW) and parallel with resistance $\mathrm{Re}$ of extra-cellular fluid (ECW). Change in the electrical Impedance of biological tissues depends on the change in tissue anatomy and tissue physiology.
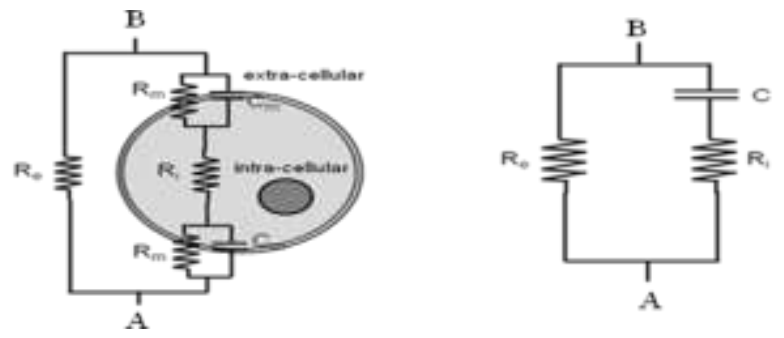

(a)
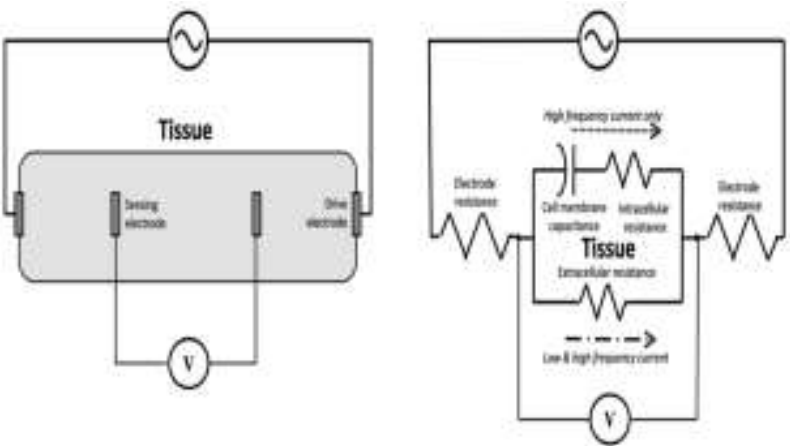

(b)

Figure 1. (a) Equivalent circuit of body cells with intra cellular fluid and extra cellular fluid;

(b) Electorde placment in body cells

Electrode placment in body cells shown in Fig.1(b), connection shows how sensing electrodes connects with body cells. The effect of low and high frequency proof that biological tissues of the human body have different impedance properties with the multifrequency current [23]. The model for the measurement of bioelectrical measurement is shown in Fig. 2. The voltage across $Z_{X}$ and $R_{S}$ becomes $U_{Z}$ and $U_{S}$ after signal processing when there is the excitation current in the circuit. The current through $Z_{X}$ and $R_{S}$ is represent as $I$ and the relationship between $\mathrm{U}_{\mathrm{Z}}$ and $\mathrm{U}_{\mathrm{S}}$ is as follows:

$\frac{U_{Z}}{U_{S}}=\frac{I \cdot Z_{X}}{I \cdot R_{S}}=\frac{Z_{X}}{R_{S}}$

...(1)

Using equation (1), it is concluded that,

$Z_{X}=R_{S} \frac{U_{Z}}{U_{S}}=R_{S} \frac{\left|U_{Z}\right| \angle \phi_{1}}{\left|U_{S}\right| \angle \phi_{2}}=R_{S} \frac{\left|U_{Z}\right|}{\left|U_{S}\right|} \angle \theta$

...(2) where $\angle \theta$ is the phase difference of $U_{Z}$ and $U_{S}$.

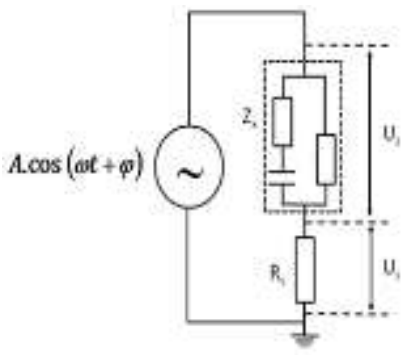

Figure 2. Model of bioelectrical Impedance measurement

The bioelectrical impedance of body tissues diversifies with the different frequency range of current implemented to them. The frequency and impedance are inversely proportional to each other. [24]. The relation between Xc (capacitive reactance) 
and $\mathrm{f}$ (frequency) is also inversely proportional; $\mathrm{Xc}$ reduced rapidly up to zero at a high or infinite frequency, similarly at zero frequency Xc act as open circuit and increase up to infinity.

$$
X_{C}=\frac{1}{2 \pi f C}=\frac{1}{\omega C}
$$

where $X_{C}=$ capacitive reactance;

$C=$ capacitance in farads $\quad f=$ frequency in Hertz The graph shows in Fig.3 represent a non-linear curve between capacitive reactance and frequency. The non-linearity of graph follows that reactance value of a capacitor is high at low frequency but as frequency starts to increase its decreases quickly. The relation between frequency and impedance is nonlinear or inversely proportional as impedance will be decreased with increment in frequency.

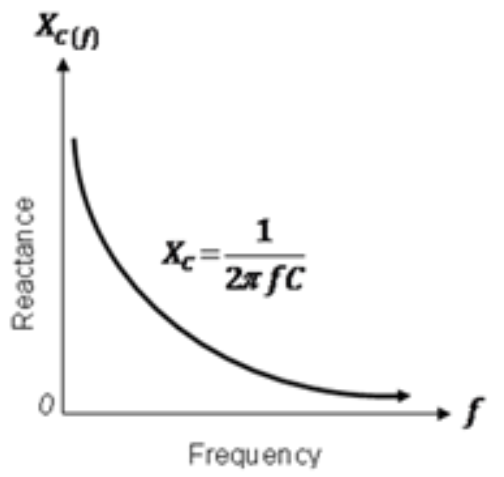

Figure 3. Capacitive Reactance against Frequency

\section{(2.2) MULTI-FREQUENCY AND SEGMENTAL} BIOELECTRICAL IMPEDANCE MEASUREMENT

In this research multi-frequency measurement technique is used for the measurment because single or low-frequency current cannot punch body tissues and only calculate the ECW value of particular segment of the body. For the estimation of both ECW and ICW; both high and low range of frequency is required. The single frequency was no able to find out the imbalance in ICW so it becoms difficult to get satisfactory results [25]. The flow of current at low and high frequencies shown in Fig.4.

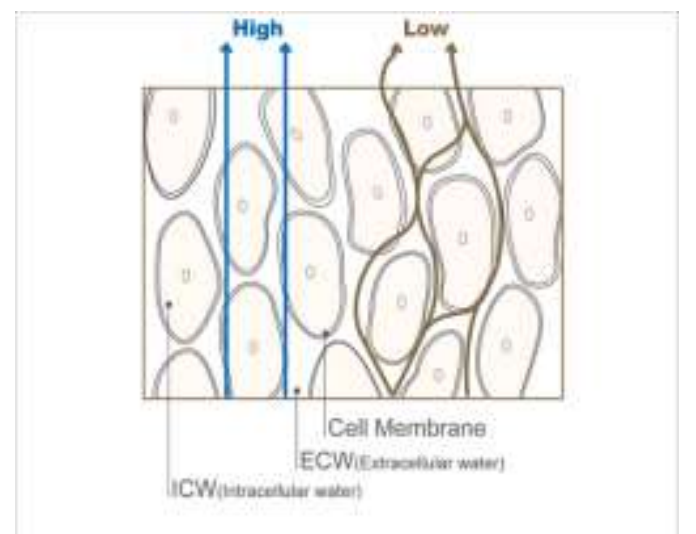

Figure 4. Path of low and high frequency current in cell membrane of body

The multi-frequency is also useful for the measurement of parameters related to body composition such as TBW, FFM, ICW, and ECW [26].

\section{(2.3) SYSTEM ARCHITECTURE}

The block diagram of developed BIA isstrumrnt shown in Fig.5 which consist Arduino microcontroller to control at the necessary action during measurment and storage, sub-miniature version-A (SMA) to alligator cable for electrodes connections, impedance measuring unit for impedance measurement, TFT LCD to display the results and power source.

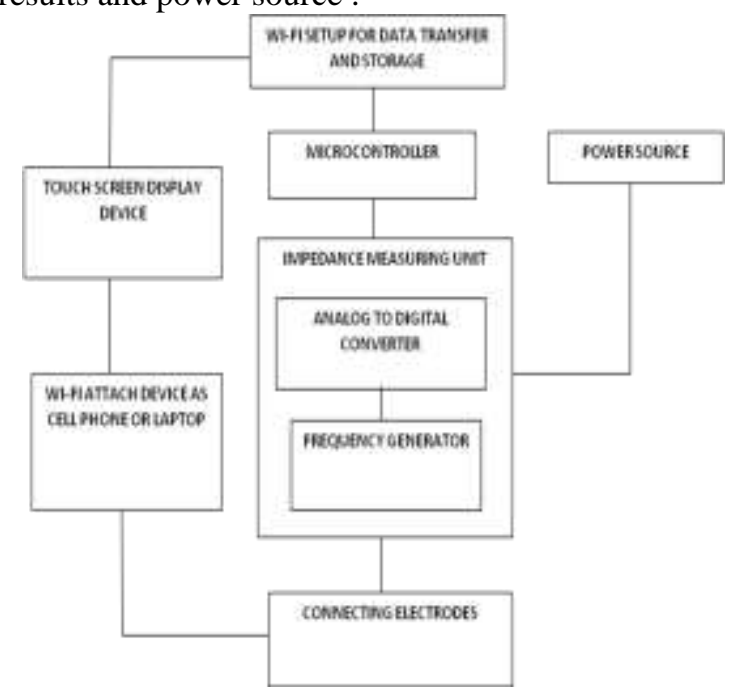

Figure 5. Block diagram of BIA instrument

\section{(2.4) ARDUINO MICROCONTROLLER}

To make the present prototype compact, ATMegha 2560 based Arduino Mega is used [3]. The length and width of ATmegha2560 inches 4 and 2.1 inches respectively. It has a total of 54 inputs and outputs 
ports, with a combination of 14 pulse width modulation (PWM) outputs and 16 analog inputs.

\section{(2.5) TFT LCD DISPLAY SCREEN}

The measured results are shown on the 2.4" inch TFT LCD colored screen. The hardware of this microcontroller consists of a resistive touch screen, an SD card slot, an Arduino shield, and a reset button. Arduino also required pre-installing the TFT library in which Arduino uses the SPI interface to use this shield.

\section{(2.6) IMPEDANCE MEASURING UNIT}

The impedance analyzer use in the present research consists of onboard frequency generator AD5933 and analog to digital converter (ADC) with a 12-bit impedance converter. The main feature of this analyzer is the measurement of the known impedance of the human body at a known frequency with the help of ADC. The output of AD5933 depends on the excitation amplitude. The range of measured impedance affects by the AD5933 chip in the respect of linearity and calibration process [27].

\section{(2.7) ELECTRODES CONNECTIONS}

The skin electrode is suitable to measure the bioelectrical impedance of upper and lower limb [28]. Because of different types of apparatus and methodology, the prediction of BIA varies with $10 \%$ of body weight. The different estimated equations with their variables are used as reference in developed method [29]. The device used in [30] has multi-lead or multi-electrodes for accurate measurement. It is also used for the measurement of volume at different segments of the body. About 200ohm unchanging impedance can provided by spherical electrodes in full range frequency, these type of electrodes show zero phases with resistive behavior. Apart from this quadrate electrodes show complex and high impedance at low frequency [31]. The bio-impedance analyzer's manufactures used electrode which minimizes the error in equipment at the right side of the human body at $50 \mathrm{kHz}$ frequency, but at high frequency when measured impedance becomes low; the error may increase. To prevent these problems low impedance electrodes are mostly suitable to use [32]. For the measurment of the segmental bio-electrical impedance of the huamn body, upper and lower limb were taken for the examination and electrodes are connected at the upper and lower side of particular segment. The placment of the electrodes for the measurment are shown in Fig.6.

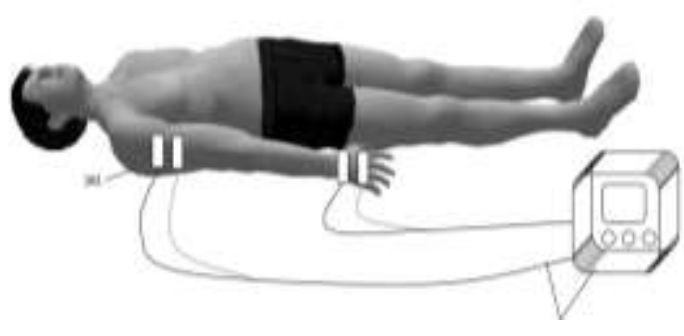

Figure 6. Position of electrodes for the impedance measurment of upper limb

\section{(2.8) SYSTEM FOR STORAGE AND DATA TRANSFER}

The main aim of the present research to make system digital in form of data storage and the transaction to the subjects whose measurement will be done. As developed prototype used to measure the bioelectrical impedance of the human body at multifrequency, so it is necessary to send measured data to the subjects as well as examiner; for the future use or research the data academically or commercially. The research uses a server base, in-build device with WIFI chip to send the data to the server. Developed BIA instrument for the analysis connectd with PC shown in Fig.7.

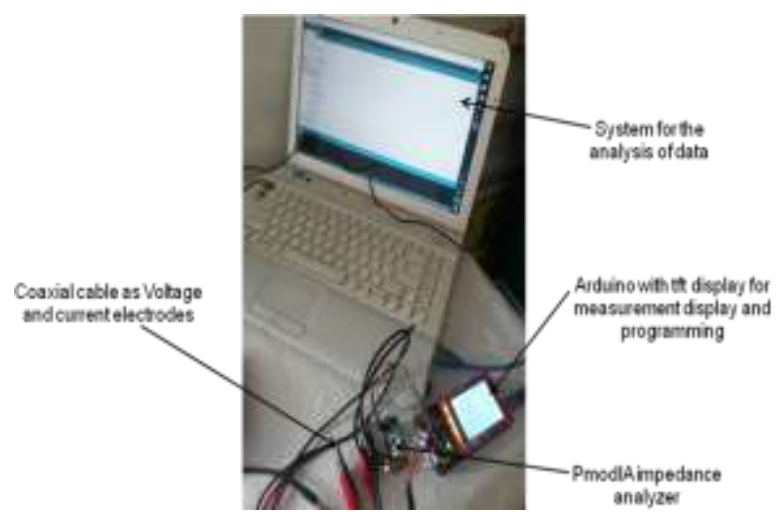

Figure 7. Experimental set up of developed BIA instrumnet with PC

\section{RESULTS}

\section{(3.1) MEASUREMENT OF IMPEDANCE IN UPPER AND LOWER LIMB}

The developed microcontroller based BIA instrument is used to measure the bioelectrical impedance of both upper and lower limb of the male subjets. Right and left arm are considered to measure impedance of upper limb, right and left leg are considered to measure impedance of the lower limb. The resulatant data measured by developed BIA instrument and 
standard device at multi frequency shown in Table.1. Graphical representation of the recorded dat shown in Fig.8. The recorded data shows that impedance of the left arm varies from $294.0 \Omega$ to $238.1 \Omega$ for the frequency range of $5-500 \mathrm{KHz}$ respectively for developed BIA instrument $290.6 \Omega$ to $235.5 \Omega$ at frequency range of $5-500 \mathrm{KHz}$ respectively for standard dveice. Similarly impedance of the right arm varies from $284.8 \Omega$ to $231.7 \Omega$ measured through BIA instrument and $283.4 \Omega$ to $229.2 \Omega$ measured through standard device, at multi-frequency range of 5-500 KHz. According to the resultant data mean error percentage between both measured instruments is less than $1.93 \Omega$ for left arm and less than $1.50 \Omega$ for the right arm.

Table.1 Validation of impedance of upper limb at multi-frequency

\begin{tabular}{|c|c|c|c|}
\hline \multirow{2}{*}{$\begin{array}{c}\text { Frequency } \\
\qquad(\mathrm{KHz})\end{array}$} & \multicolumn{3}{|c|}{ Left $\operatorname{Arm}(\Omega)$} \\
\hline & $\begin{array}{c}\text { Standard } \\
\text { Device }\end{array}$ & $\begin{array}{c}\text { BIA } \\
\text { Instrument }\end{array}$ & $\begin{array}{l}\text { Error } \\
\text { (in \%) }\end{array}$ \\
\hline 5 & 290.6 & 294.4 & 1.31 \\
\hline 50 & 279.9 & 283.7 & 1.36 \\
\hline 100 & 272.5 & 277.6 & 1.87 \\
\hline 250 & 254.8 & 259.7 & 1.92 \\
\hline 500 & 235.5 & 238.1 & 1.10 \\
\hline \multirow{2}{*}{$\begin{array}{c}\text { Frequency } \\
\qquad(\mathrm{KHz})\end{array}$} & \multicolumn{3}{|c|}{ Right $\operatorname{Arm}(\Omega)$} \\
\hline & $\begin{array}{l}\text { Standard } \\
\text { Device }\end{array}$ & $\begin{array}{c}\text { BIA } \\
\text { Instrument }\end{array}$ & $\begin{array}{l}\text { Error } \\
\text { (in \%) }\end{array}$ \\
\hline 5 & 283.4 & 284.8 & 0.49 \\
\hline 50 & 273.6 & 275.7 & 0.77 \\
\hline 100 & 267.4 & 270.2 & 1.05 \\
\hline 250 & 249.3 & 252.4 & 1.24 \\
\hline 500 & 229.2 & 231.7 & 1.09 \\
\hline
\end{tabular}

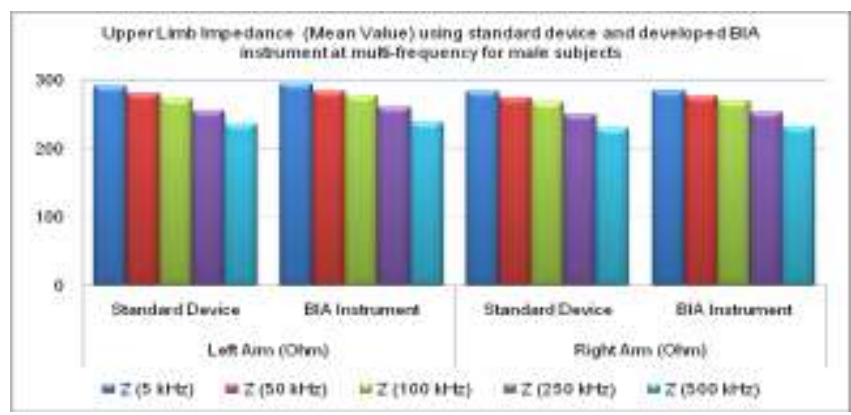

Figure 8. Plot represents comparative analysis of upper limb impedance at multi-frequency
The resltant impedance analysis of lower limb, shows that impedance of the right lef varies from $282.4 \Omega$ to $225.3 \Omega$ for data measured by developed BIA instrument and $273.1 \Omega$ to $219.9 \Omega$ for the data measured by standard device at multi-frequency. The Resultant data shows that mean error percentage in the data recorded from developed BIA instrument and standaerd dveice is less than $3.37 \Omega$ for left leg and less than $2.78 \Omega$ for right leg at same fequencies.

Table.2 Validation of impedance of lower limb at multi-frequency

\begin{tabular}{|c|c|c|c|}
\hline \multirow{2}{*}{$\begin{array}{c}\text { Frequency } \\
(\mathrm{KHz})\end{array}$} & \multicolumn{3}{|c|}{ Left leg $(\Omega)$} \\
\cline { 2 - 4 } & $\begin{array}{c}\text { Standard } \\
\text { Device }\end{array}$ & $\begin{array}{c}\text { BIA } \\
\text { Instrument }\end{array}$ & $\begin{array}{c}\text { Error } \\
\text { (in \%) }\end{array}$ \\
\hline 5 & 266.3 & 275.1 & 3.30 \\
\hline 50 & 259.1 & 267.3 & 3.16 \\
\hline 100 & 250.8 & 256.9 & 2.43 \\
\hline 250 & 230.6 & 237.1 & 2.82 \\
\hline 500 & 211.2 & 218.3 & 3.36 \\
\hline Frequency & & Right leg $(\Omega)$ & \\
\cline { 2 - 4 }$(\mathrm{KHz})$ & $\begin{array}{c}\text { Standard } \\
\text { Device }\end{array}$ & $\begin{array}{c}\text { BIA } \\
\text { Instrument }\end{array}$ & $\begin{array}{c}\text { Error } \\
\text { (in \%) }\end{array}$ \\
\hline 5 & 273.1 & 282.4 & 3.41 \\
\hline 50 & 267.2 & 274.6 & 2.77 \\
\hline 100 & 259.6 & 266.8 & 2.77 \\
\hline 250 & 240.9 & 246.1 & 2.16 \\
\hline 500 & 219.9 & 225.3 & 2.46 \\
\hline
\end{tabular}

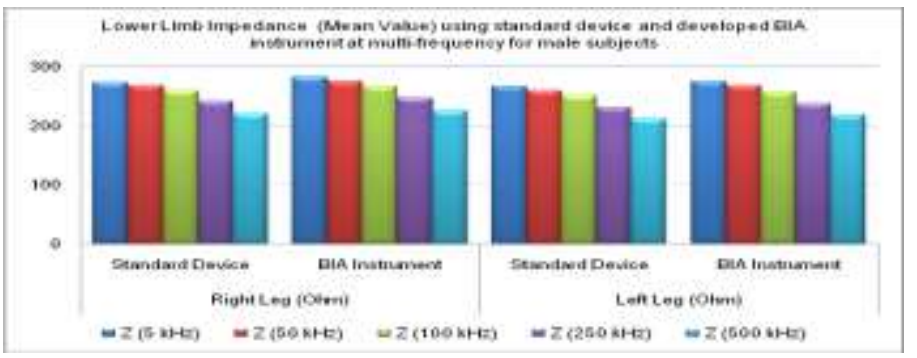

Figure 9. Plot represents comparative analysis of lower limb impedance at multi-frequency

The observation of the measured data defines that the impedance of left limb is always greater than right limb. The impedance of both upper and lower limb are measured at the same frequency. 


\section{INTERFACING SOFTWARE/ FLOW CHART:}

The flow chart shows in Fig.10 shows the basic algorithm of the impedance measurement.

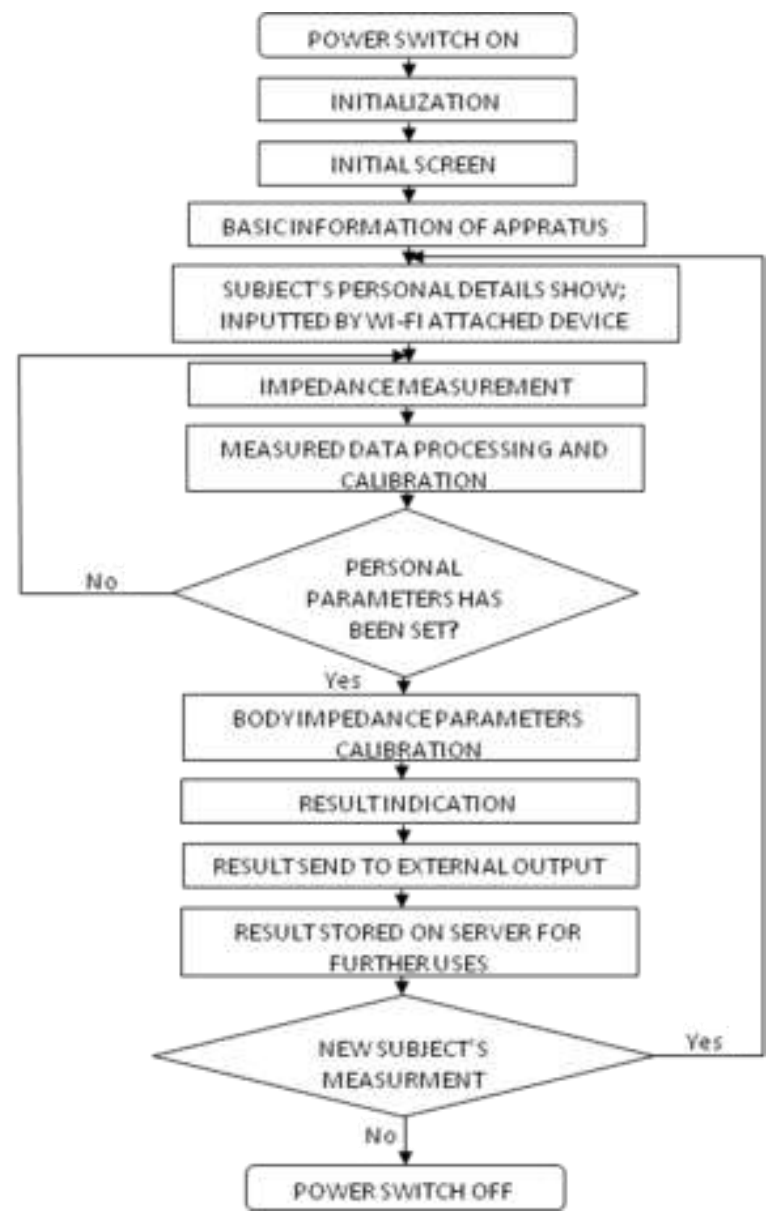

Figure 10. Flow chart of the impedance measurement

algorithm

\section{DISCUSSION}

The developed BIA instrument can be useful for convenience of most of the population with their advantageous features as it can be carrying anywhere because it is compact in size and provide real-time measurement to take quick decision for the appropriate treatment. The resultant data recorded through the developed device shows that impedance of the particular segment decreases with the increase frequency. According to the recorded data impedance of the left limb is greater than the right limb although the muscles of the right limb are stronger than the left muscles.

The validation analysis of the data measured through developed BIA instrument and Standard device represent that mean error percentage is less than $1.93 \Omega$ for left arm and less than $1.50 \Omega$ for the right $\mathrm{arm}$. The mean error percentage for the left leg is less than $3.37 \Omega$ and less than $2.78 \Omega$ for the right leg at the same frequencies.

\section{ADVANTAGES/DISADVANTAGES}

\section{(6.1) ADVANTAGES OF PROPOSED DEVICE}

Cost-Effective: The device proposed in this research detects estimated risks at a low cost.

Pocket size: The proposed device has small size like a cell phone.

Early detection: The device is useful to detect body diseases at early stage with daily monitoring.

Fitness scale: To identify limits of physical workout for particular according to their capability.

Acceptance: The proposed device easily accepted by everyone related to the medical field including clinical and laboratory, sports, nutrition, and psychology.

Fast response: The proposed device is very fast as it is a real-time monitoring device.

Quick and Reliable: The prototype gives a quick and reliable additional assessment.

\section{DISADVANTAGES OF PROPOSED DEVICE}

1. Need of height and Weight measurement within prototype.

2. The Prototype provides a Wi-Fi facility to transfer data so required printable reports.

\section{CONCLUSION}

The summary of the overall study presents that BIA is the simplest method to measure the bio-electrical impedance of upper and lower limb for the male subjects. The developed BIA instrument can be more demandable because of its compact size with less weight. The present research concludes that impedance of the human limb decreases with increases frequency range and impedance of the left limb is greater than the impedance of right limb at each frequency. The BIA is more popular in the field of medical, academic research and daily routine life of a normal population to protect them from a different type of disease at early stage. The present research also can add more features in the developed BIA instrument in the future for the measurement of other related parameters. The developed BIA instrument could able to measure other body composition parameters in the future for more applications.

\section{ACKNOWLEDGMENTS}

The authors would like to thanks to the participants of this study. The authors would like to acknowledge 
Dr. Dev Singh for his valuable assistance in research. We would also like to thank the Head of medicine department of GSVM, Kanpur; Dr.Richa Giri for their assistance in the data collection procedure.

\section{REFERENCES}

[1] Gao, X., \& Tang, J. (2011). Human Bioelectrical impedance Measuring Method Based on Principle of Multi-frequency and Multi-segment. Procedia Engineering, 24, 459-463.

[2] Khan, Ghazala Perveen, Munna Khan, and Shabana Mehfooz. "Generalized sex and age specific body composition prediction equations for Indian subjects." International Journal of Computational Engineering Research 3.12 (2013): 1-15.

[3] Khan, M., Sirdeshmukh, S. P. S. M. A., \& Javed, K. (2016). Evaluation of bone fracture in animal model using bio-electrical impedance analysis. Perspectives in Science, 8, 567-569.

[4] Coggon, D., et al. "Knee osteoarthritis and obesity." International journal of obesity 25.5 (2001): 622.

[5] Baik, S. W., Kim, Y. J., Kim, J. H., Jang, W. Y., Kim, S. S., Park, G. C \& Jeon, G. R. (2014). Implementation of Bioelectric Impedance Measurement System using MultiFrequency Applying Method and TwoElectrode Method. Biomedical and Environment Engineering (ICCBEE'14), 1015.

[6] Wills, Andrew K., et al. "Life course body mass index and risk of knee osteoarthritis at the age of 53 years: evidence from the 1946 British birth cohort study." Annals of the rheumatic diseases 71.5 (2012): 655-660.

[7] Pacca, Daniel Moreira, et al. "Prevalence of joint pain and osteoarthritis in obese brazilian population." ABCD. Arquivos Brasileiros de Cirurgia Digestiva (São Paulo) 31.1 (2018).

[8] Chinen, Koyu, et al. "New equivalentelectrical circuit model and a practical measurement method for human body impedance." Bio-medical materials and engineering 26.s1 (2015): S779-S786.

[9] Khan, Munna, Shabana Mehfuz, and Ghazala PerveenKhan. "Bioelectrical Impedance Analysis (BIA) For Assessing Tbw and Ffm of Indian Females." Editorial Committees: 1.

[10] Kamat, D. K., and P. M. Patil. "Multifrequency and multi-segment bio-impedance measurement using tetra-polar electrode setup." 2016 2nd International Conference on Control Science and Systems Engineering (ICCSSE). IEEE, 2016.

[11] Chen, B., Zhang, X., \& Liu, N. (2009, October). Research and design of human impedance measuring instrument based on the method of multi-frequency and Multisegment. In 2009 2nd International Conference on Biomedical Engineering and Informatics (pp. 1-4). IEEE.

[12] Wingo, B. C., Barry, V. G., Ellis, A. C., \& Gower, B. A. (2018). Comparison of segmental body composition estimated by bioelectrical impedance analysis and dualenergy X-ray absorptiometry. Clinical nutrition ESPEN, 28, 141-147.

[13] Ling, C. H., de Craen, A. J., Slagboom, P. E., Gunn, D. A., Stokkel, M. P., Westendorp, R. G., \& Maier, A. B. (2011). Accuracy of direct segmental multi-frequency bioimpedance analysis in the assessment of total body and segmental body composition in middle-aged adult population. Clinical nutrition, 30(5), 610-615.

[14] de Castro, J. A. C., de Lima, T. R., \& Silva, D. A. S. (2018). Body composition estimation in children and adolescents by bioelectrical impedance analysis: A systematic review. Journal of bodywork and movement therapies, 22(1), 134-146.

[15] Cannon, T., \& Choi, J. (2019). Development of a Segmental Bioelectrical Impedance Spectroscopy Device for Body Composition Measurement. Sensors, 19(22), 4825.

[16] Wingo, B. C., Barry, V. G., Ellis, A. C., \& Gower, B. A. (2018). Comparison of segmental body composition estimated by bioelectrical impedance analysis and dualenergy X-ray absorptiometry. Clinical nutrition ESPEN, 28, 141-147.

[17] Wu, Chun-Shien, et al. "Predicting body composition using foot-to-foot bioelectrical impedance analysis in healthy Asian individuals." Nutrition journal 14.1 (2015): 52.

[18] Ragini, B., Aishwarya, S. R., Tamil Selvan, M., Pillai, A., \& Anburajan, M. (2015). Prediction of body fat using segmental body composition by bioelectrical impedance in the evaluation of obesity. Journal of Engineering and Applied Sciences, 10(8), 3627-3634

[19] Utter, Alan C., et al. "Use of the leg-to-leg bioelectrical impedance method in assessing body-composition change in obese women." The American journal of clinical nutrition 69.4 (1999): 603-607.

[20] Grisbrook, T. L., et al. "Alternate electrode placement for whole body and segmental bioimpedance spectroscopy." Physiological measurement 36.10 (2015): 2189.

[21] Alvarenga, R. L., and M. N. Souza. "Assessment of knee osteoarthritis by bioelectrical impedance." Proceedings of the 25th Annual International Conference of the IEEE Engineering in Medicine and Biology Society (IEEE Cat. No. 03CH37439). Vol. 4. IEEE, 2003. 
[22] YANOVSKI, S. Z., HUBBARD, V. S., HEYMSFIELD, S. B., \& LUKASKI, H. C. (1996). Bioelectrical impedance analysis in body composition measurement: National institutes of health technology assessment conference statement. The American journal of clinical nutrition, 64(3), 524S-532S.

[23] Hui, L., \& Ding, L. W. (2010, August). Lowpower and portable design of bioelectrical impedance measurement system. In 2010 WASE International Conference on Information Engineering (Vol. 3, pp. 38-41). IEEE.

[24] Cornish, B. H., Thomas, B. J., \& Ward, L. C. (1993). Improved prediction of extracellular and total body water using impedance loci generated by multiple frequency bioelectrical impedance analysis. Physics in Medicine \& Biology, 38(3), 337.

[25] Hannan, W. J., Cowen, S. J., Fearon, K. C. H., Plester, C. E., Falconer, J. S., \& Richardson, R. A. (1994). Evaluation of multi-frequency bio-impedance analysis for the assessment of extracellular and total body water in surgical patients. Clinical science, 86(4), 479-485.

[26] https://www.robotshop.com/media/files/pdf/ar duinomega2560datasheet.pdf

[27] Al-Ali, A., Elwakil, A. S., Ahmad, A., \& Maundy, B. (2017, February). Design of a Portable Low-Cost Impedance Analyzer. In BIODEVICES (pp. 104-109).

[28] Kim, K. S., et al. "A new bio-impedance sensor technique for leg movement analysis." Proceedings of the 2004 Intelligent Sensors, Sensor Networks and Information Processing Conference, 2004.. IEEE, 2004.

[29] J Joshi, Ms Shruti R., and U. R. Bagal. "Development of Bioelectrical impedance analyzer for Body composition analysis." IOSR Journal of Electrical and Electronics Engineering (IOSRJEEE) 9.5 (2014): 53-62.

[30] Kamat., D. K., Shende, Vishakha, Patil, P. M., (2015). Measurement System for Bioimpedance Signal Analysis using Impedance Analyzer, International Journal of Engineering Research \& Technology (IJERT) ISSN: 22780181, Vol. 4 Issue 07.

[31] Corbellini, S., \& Vallan, A. (2014, June). Arduino-based portable system for bioelectrical impedance measurement. In 2014 IEEE International Symposium on Medical Measurements and Applications (MeMeA) (pp. 1-5). IEEE.

[32] Bogónez-Franco, P., Nescolarde, L., McAdams, E., \& Rosell-Ferrer, J. (2014). Multifrequency right-side, localized and segmental BIA obtained with different bioimpedance analysers. Physiological measurement, 36(1), 85.

[33] Mialich, M. S., Sicchieri, J. F., \& Junior, A. J. (2014). Analysis of body composition: a critical review of the use of bioelectrical impedance analysis. Int J Clin Nutr, 2(1), 110. 